\title{
Bridge Structures with GFRP Composite Deck
}

\author{
Beata Stankiewicz \\ Department of Roads \& Bridges, Faculty of Civil Engineering, Opole University of Technology, Opole, Poland \\ Email: b.stankiewicz@po.opole.pl
}

Received 7 February 2015; accepted 25 February 2015; published 26 February 2015

Copyright (C 2015 by author and Scientific Research Publishing Inc.

This work is licensed under the Creative Commons Attribution International License (CC BY). http://creativecommons.org/licenses/by/4.0/

(c) (i) Open Access

\begin{abstract}
In this paper, author's first part of research of GFRP bridge deck (using ASSET fiber line composite modular system) took part at AGH University of Science and Technology Laboratory of Glass Technology and Amorphous Coatings Department. The analysis consisted spectrometer analysis of chemical constitution of glass fiber, identification of material according to Fourier spectroscopy, electronic scan microscopy (SEM/EDAX) and DTA analysis. The modal FEM analysis of chosen footbridge with light GFRP deck has been presented in the paper.
\end{abstract}

\section{Keywords}

GFRP Bridge Deck by Material Analysis, Modal Analysis of Footbridge Composite Deck

\section{Introduction}

Good exploration of new materials, like composite GFRP, creates possibility to improve this technology and makes comparison analysis with traditional standard of materials. Composite materials are the future of building structures. Durability of structures is always a very important parameter. The past applications of CFRP in bridge structures like improving tapes, lines (wants) of cable stayed bridges have given open gate for composite materials. GFRP-polymer with glass fibre is a good alternative for traditional material. The properties of GFRP are: anisotropy (depending on the type of reinforcement), low density, physical and mechanical properties of composite depending on its components and their respective proportions, high resistance to corrosion and oxidation, relatively high mechanical properties and ability to form complex shapes. Relatively low cost comparing to other kinds of fibres makes E-glass fibres the most commonly used fibres available in the construction industry. The disadvantages of glass fibres are a relatively low Young's modulus, the low humidity and alkaline resistance as well as low long-term strength due to stress rupture. GFRP composite material is suitable for decks of bridge structures and footbridges applications. The topic about GFRP pultruted bridge decks is the focus of $\mathrm{H}$. 
Zobel's and W. Karwowski's research. Anisotropic GFRP is connected with steel or prestressed concrete main bridge beams. Ki-Tae Park, Yoon-Koog Hwangi, Hyeong-Yeol Kim have used various connectors in models of bridge structures and in situ investigation. There is an interesting science filed of bridge structures with GFRP deck. European researchers T. Keller, H. Gürtler, W. Sebastian, J. Knippers prefer adhesive system between main bridge beam and composite deck, using epoxy glue. T. Keller, as the first in Europe, has published the results of scanning analysis of GFRP Fiberline composite material [1] [2]. The researches based on laboratory models of DuraSpan composite orthotropic bridge system and FEM complex analysis have been created by J. Lesko, K. Turner and J. Harris. Vovesny, M. and Rotter, T. have published the results of research of temporary bridge structures using deck panels made by glass fiber reinforced polymer [3].

Anisotropic character of GFRP composite has been investigated and described in the paper. GFRP modular deck has been used in own project of footbridge. The natural frequency and vibrations with amplitudes of chosen footbridge can equal to the values recommended in EN 1990/A1.

\section{Material Analysis of GFRP Bridge Deck}

The author's first part of research of GFRP bridge deck (using ASSET Fiberline composite modular system) took part at AGH University of Science and Technology Laboratory of Glass Technology and Amorphous Coatings Department. The analysis consisted of:

- spectrometer analysis of chemical constitution of glass fiber in polymer matrix, using ICP-MS Elan 61,000 by Perkin Elmer,

- identification of material according to Fourier spectroscopy in infrared with FTS-60 MV Bio-Rad,

- electronic scan microscopy (SEM/EDAX) for estimate of morphology of composite, using Nora Nano-SEM (Figure 1),

- DTA analysis for estimation of physical and chemical transformation of glass fiber, with Perkin Elmer DTA-7 Series.

Composite material was tempered to $450^{\circ} \mathrm{C}$ for isolation of glass fibers (Figure 1), which have been analyzed by DTA at chemical investigation and microscopy exploration. On DTA base (Figure 2), the temperature of glass transformation is $T_{g}=703^{\circ} \mathrm{C}$, the temperature of dilometric soften is $T_{d}=852^{\circ} \mathrm{C}$. Table 1 has showed chemical content of glass fibers.

According to thermal analysis DTA and research of chemical content the main conclusion has been investigated, is that glass fiber is ECR type of glass. As complementary research EDAX analysis has been used for single fiber (Figure 3). Observation of morphology, surface of fiber and configuration has been possible using scanning microscope SEM. The isolation fibers by scanning analysis have been showed as number 1, 2 and 3

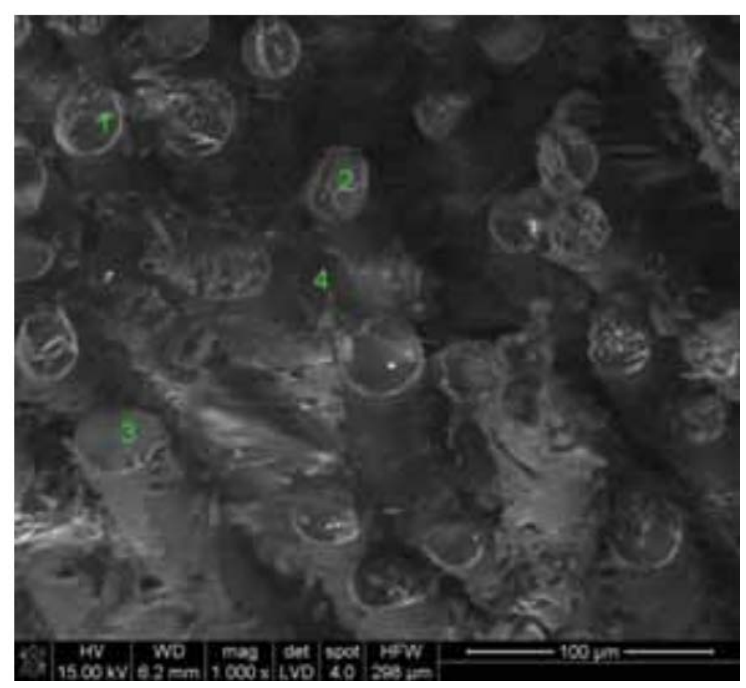

(a)

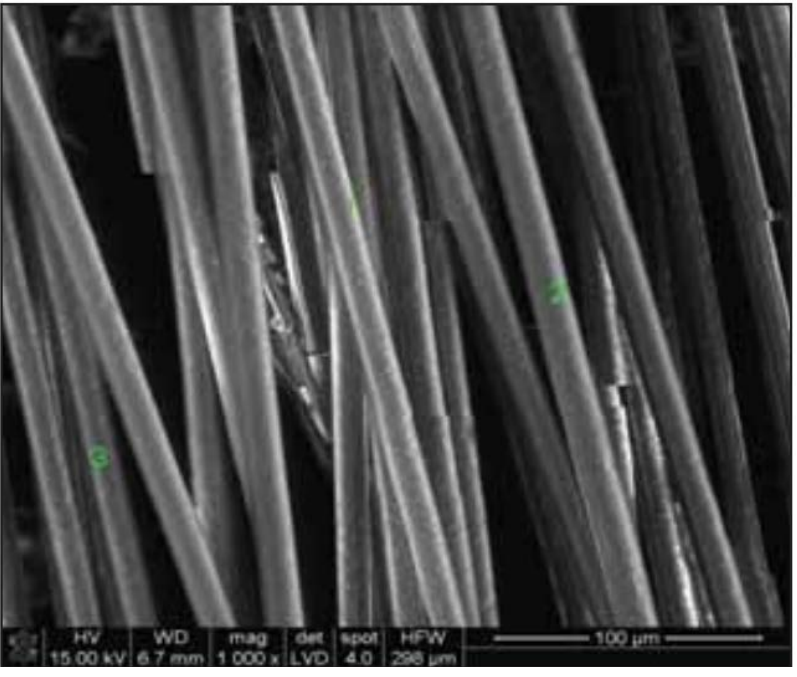

(b)

Figure 1. Microstructure of GFRP panel deck: (a) Cross section of composite; (b) Individual fibers of GFRP in polymer matrix. 


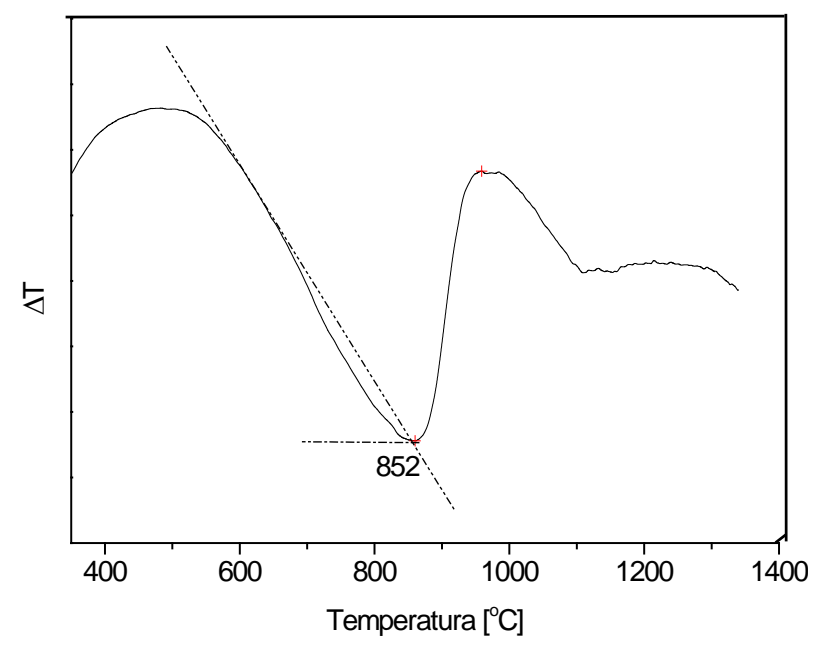

Figure 2. DTA curve for single glass fiber from composite.

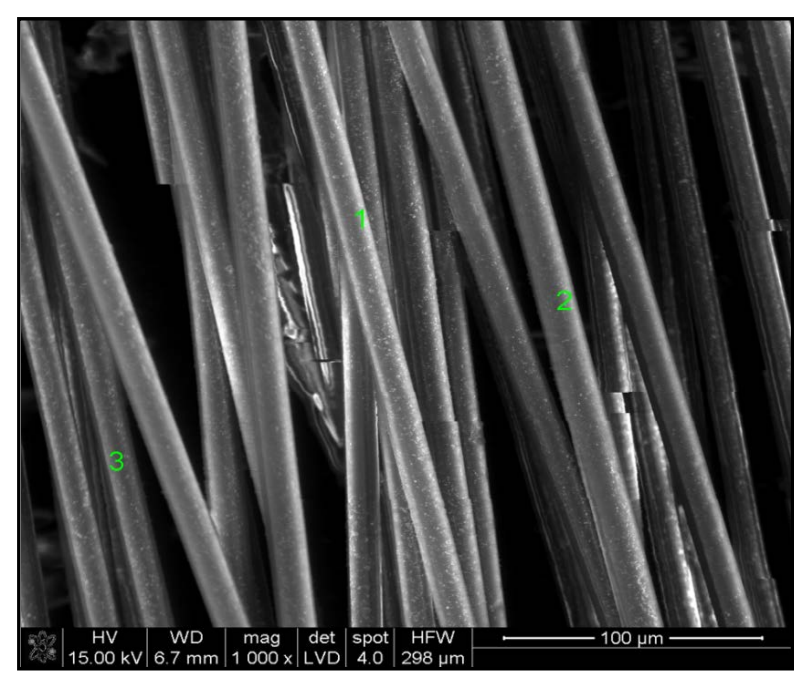

Figure 3. Anisotropic structure of composite on glass fibers base.

Table 1. The results of analysis for glass fiber (oxide content).

\begin{tabular}{ccc}
\hline Oxide & Content [\%] \\
$\mathrm{SiO}_{2}$ & 55.33 \\
$\mathrm{Al}_{2} \mathrm{O}_{3}$ & 14.12 \\
$\mathrm{CaO}$ & 24.02 \\
$\mathrm{Fe}_{2} \mathrm{O}_{3}$ & 0.71 \\
$\mathrm{Na}_{2} \mathrm{O}$ & 0.40 \\
$\mathrm{~K}_{2} \mathrm{O}$ & 0.42 \\
$\mathrm{TiO}_{2}$ & 1.80 \\
$\mathrm{MgO}$ & 1.2 \\
$\mathrm{ZnO}$ & 2.0 \\
$($ Summary $)$ & 100 \\
\hline
\end{tabular}


(Figure 3). EDAX analysis of chemical elements at fiber's surface by points 1 - 3 has been showed on Figures 4-6.

Fourier spectroscopy in infrared is useful for complex identification a type of matrix using to connect conglomerate of fibers on structure elements. IR spectrum view describes material of matrix in Figure 7 [4].

The paths in from $3084-2586 \mathrm{~cm}^{-1}$ are characteristic of both for epoxy and polymer material. But the path in $1734 \mathrm{~cm}^{-1}$ is characteristic for polyester. The path of absorption frequency at $1734 \mathrm{~cm}^{-1}$ is compatible with vibration $\mathrm{C}=\mathrm{O}$ found in ester group but the path of absorption with frequency $3447 \mathrm{~cm}^{-1}$ is suitable with $\mathrm{OH}$ alcohol group. Double absorption paths with frequency $2930 \mathrm{~cm}^{-1}$ and $2856 \mathrm{~cm}^{-1}$ has connected with symmetric vibration $=\mathrm{CH}_{2}$. The matrix of glass fibers consists of epoxy resin with amine bisphenol A and epoxy polyester aliphatic by isophthalic polyester. The fiber fractions are approximately $50 \%$ per volume or $70 \%$ per weight. The matrix is a protecting cover for fiber and it is responsible for load propagation [4] [5].

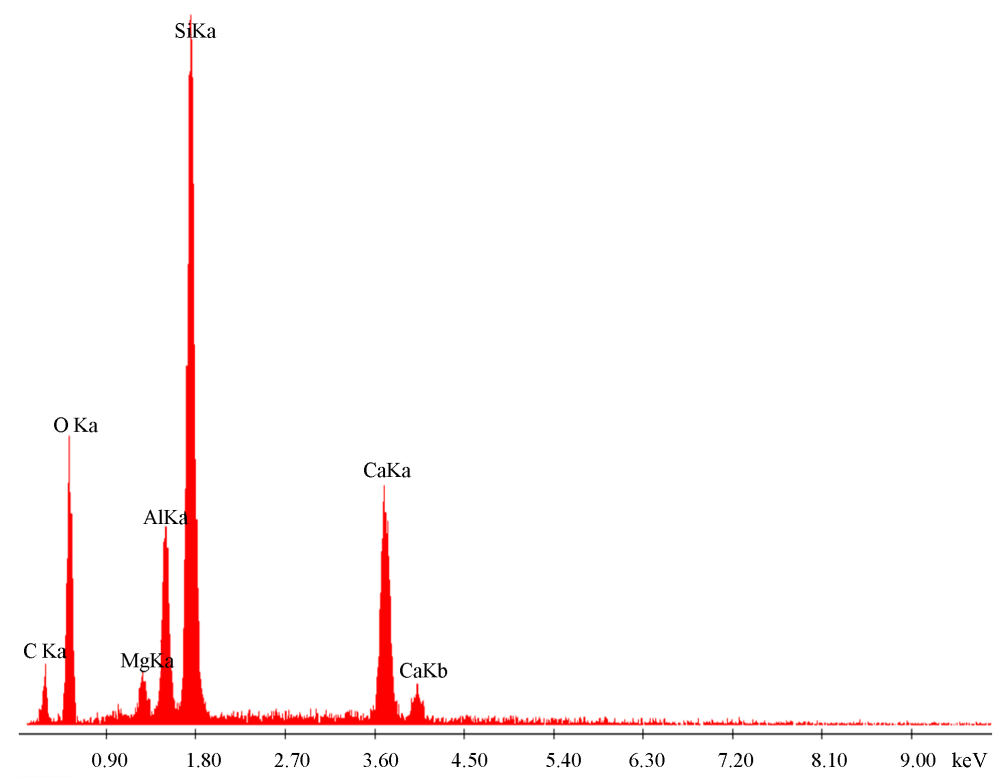

Figure 4. EDAX analysis in point 1 (fiber ECR glass number 1).

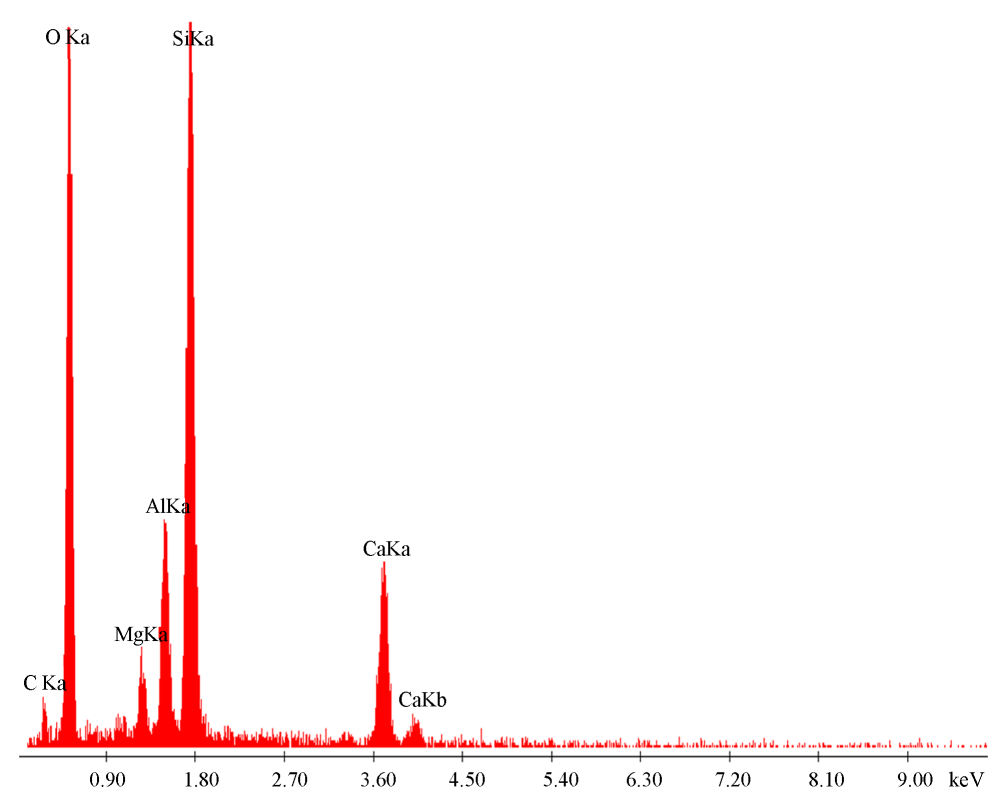

Figure 5. EDAX analysis in point 2 (fiber ECR glass number 2). 


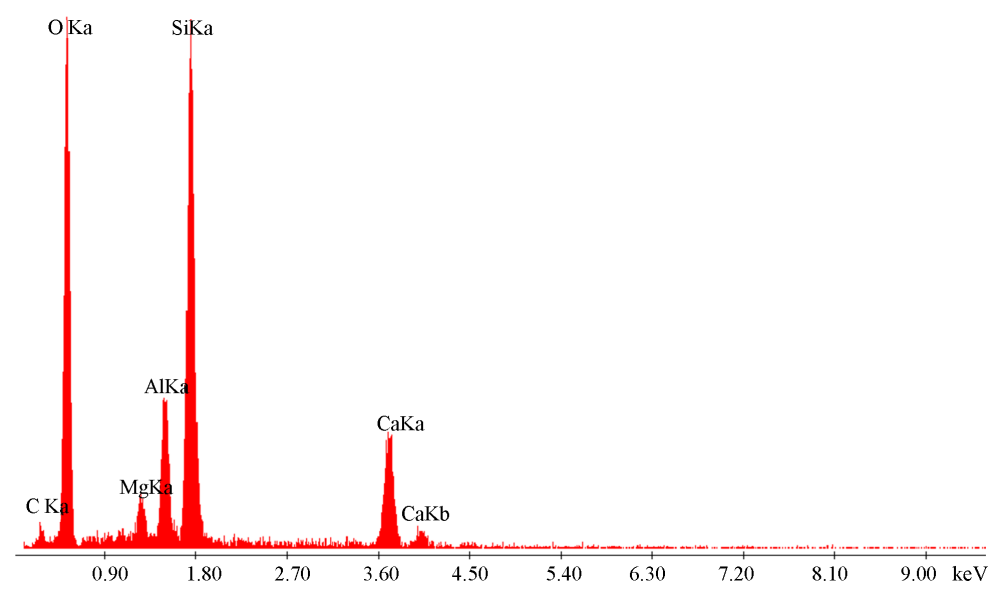

Figure 6. EDAX analysis in point 3 (in glass fiber ECR number 3).

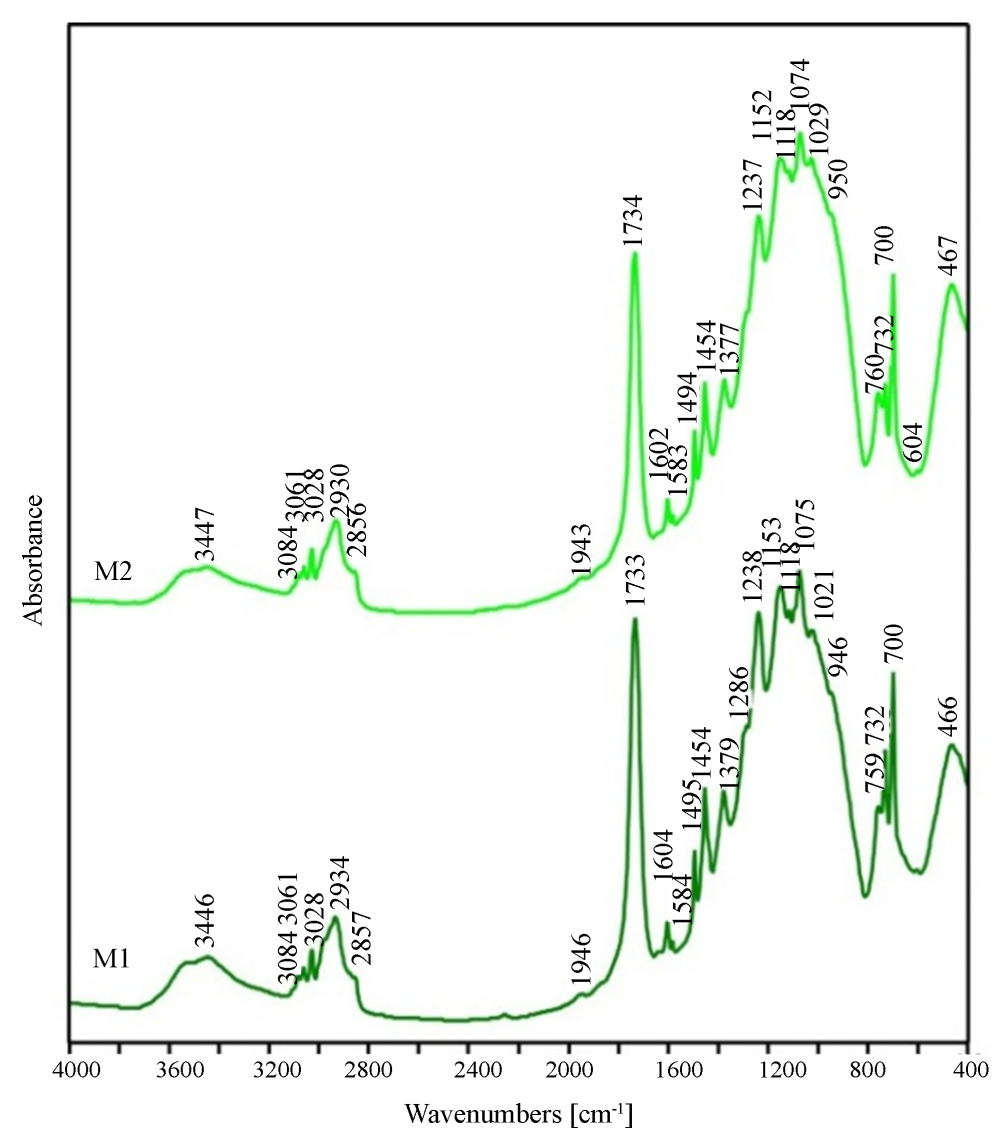

Figure 7. The spectrum of IR matrix.

\section{The Analysis of Chosen Footbridge with Light GFRP Deck}

The existed footbridge in Opole, constructed by laminated wood main beams and wood deck with steel profiles, has been replaced to footbridge with GFRP Fiberline HD deck system.

The footbridge of medium size has been located at Bolko Island, in a park and in one district of Opole (Figure 8), after revitalization cycle. This is a structure with two independent spans consists of free ends on the wooden main beams. That kind of footbridge is very suitable to outside areas of city centres and among green natural area of park. The conception of footbridge with GFRP deck is the solution for a longer durable and sim- 
ple deck.

The key points of numerical FEM analysis have been verified the collaboration between GFRP elements (by Fiberline HD deck system) with main beams (by laminated wood GL32C) of footbridge structure. The comparison analysis has been provided for existed wooden deck and hypothetical composite deck. The basic view of footbridge is in Figure 9, cross section of two conceptions is in Figure 10. The three $1^{\text {st }}$ modes and corresponding frequencies have been showed in Figure 11 for footbridge with GFRP deck. The dynamic investigation according to modal analysis, for wood deck has been summarized in Figure 12.

Table 2 consists of natural frequencies for both kinds of decks. Important data base parameters of GFRP deck by Fiberline HD system-Modulus of Elasticity: 23,000 MPa, weight: $8530 \mathrm{~g} / \mathrm{m}$, height: $\mathrm{H}=40 \mathrm{~mm}$, shear

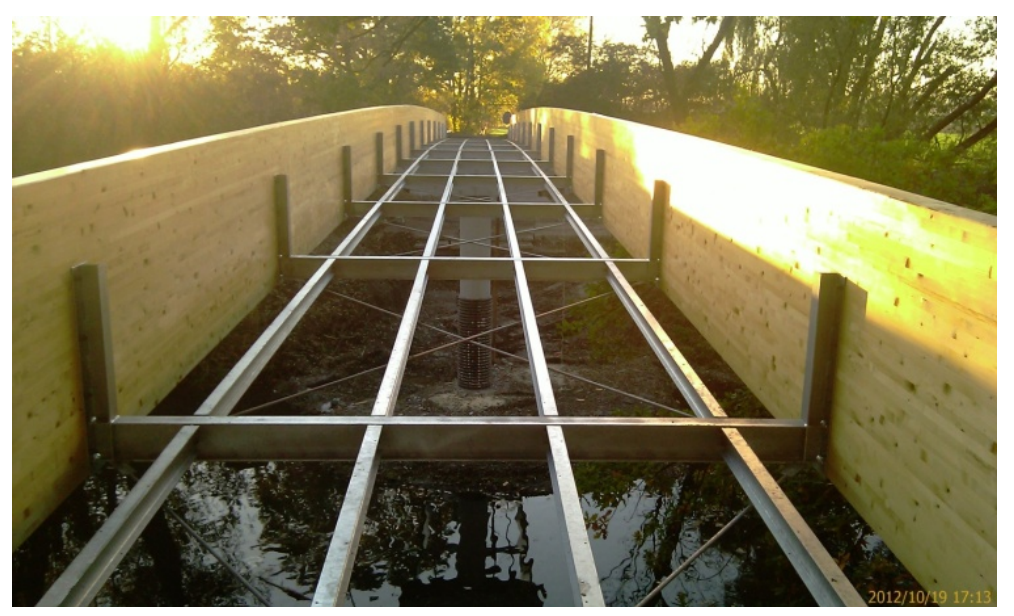

Figure 8. Footbridge in Opole (during erection) used to FEM analysis.

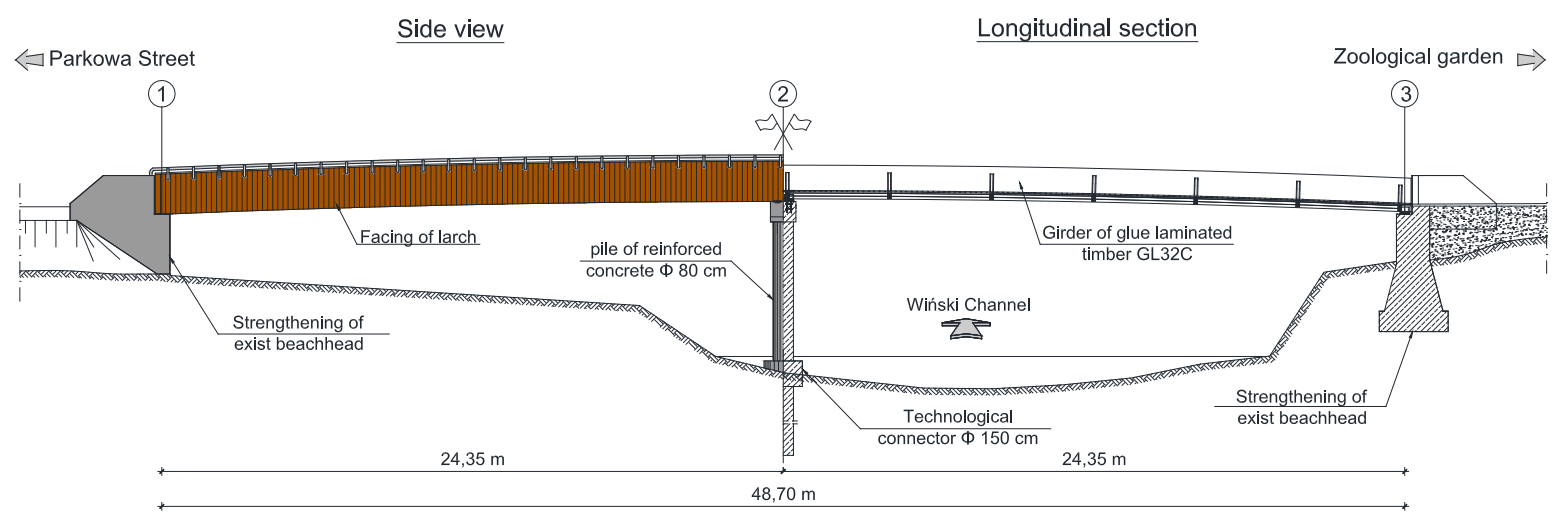

Figure 9. The main elements of footbridge in Opole at Bolko Island.
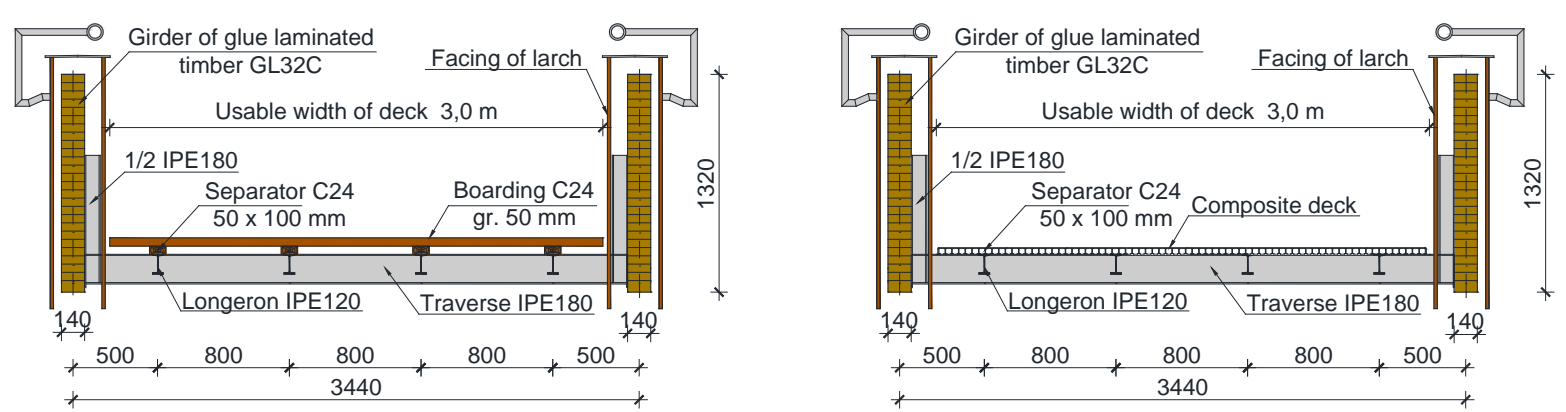

Figure 10. Two conceptions of footbridge deck using wooden panels (left) and GFRP panels (right). 
modulus: $3000 \mathrm{MPa}$. Light orthotropic deck is promising alternative opposite traditional material, opposite typical standard of structure. The FEM analysis has showed it in simple, basic investigation. Potential high resistance to corrosion of GFRP deck and longer durability create better alternative of such kind of bridge deck.

The dynamic response has been verified according to footfall, using $70 \mathrm{~kg}$ person weight and $2.0 \mathrm{~Hz}$ frequency. That kind of analysis has been applied for both types of deck, too. The pedestrian-inducted vibrations and all comparison effects have been presented in Figure 13 \& Figure 14 and in Table 3 [6].

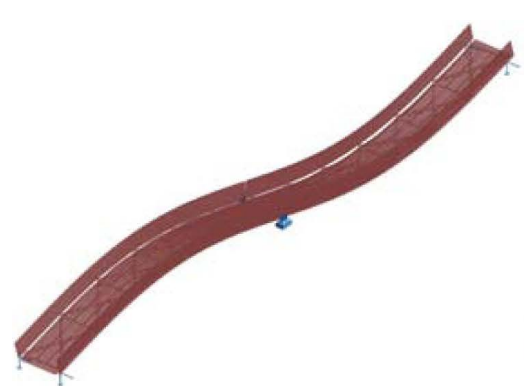

$\mathrm{f}_{1}=4.88 \mathrm{~Hz}$

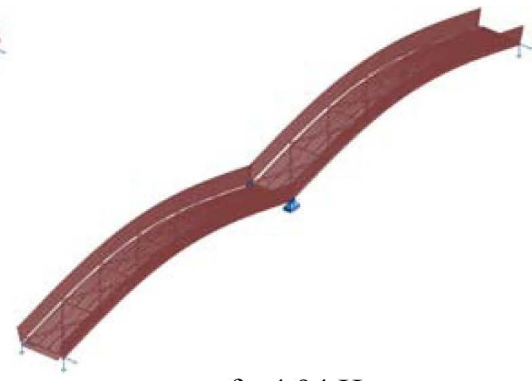

$\mathrm{f}_{2}=4.94 \mathrm{~Hz}$

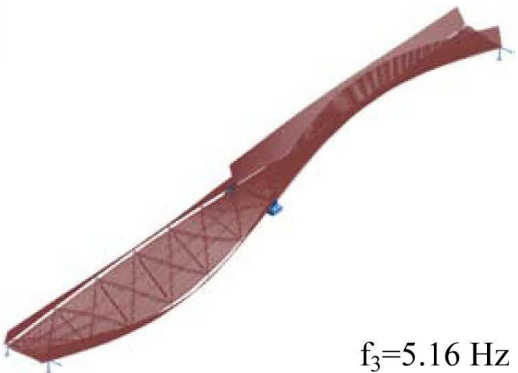

$\mathrm{f}_{3}=5.16 \mathrm{~Hz}$

Figure 11. Identified the $1^{\text {st }}$ three modes for footbridge with GFRP deck.

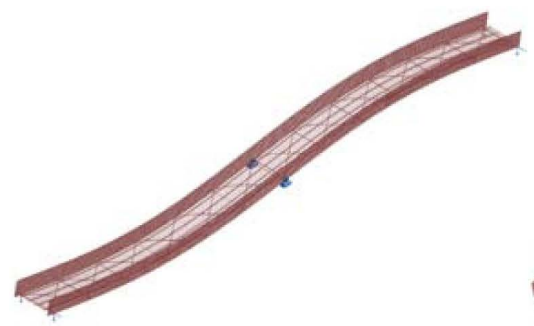

$\mathrm{f}_{1}=4.42 \mathrm{~Hz}$

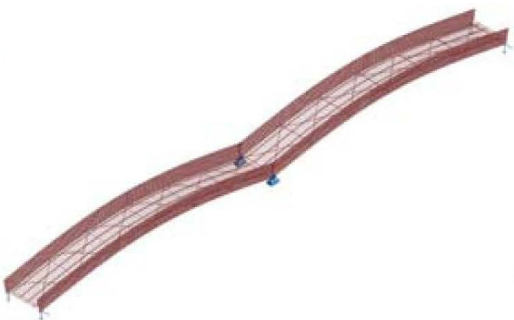

$\mathrm{f}_{2}=4.48 \mathrm{~Hz}$

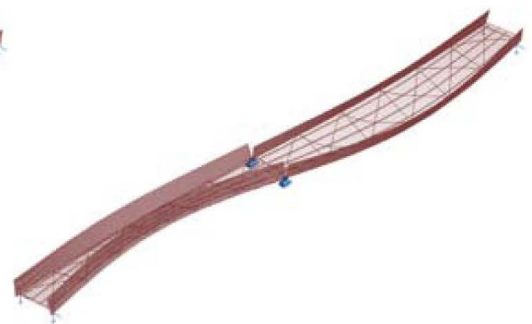

$\mathrm{f}_{3}=5.34 \mathrm{~Hz}$

Figure 12. Identified modes shape for footbridge with wooden deck.
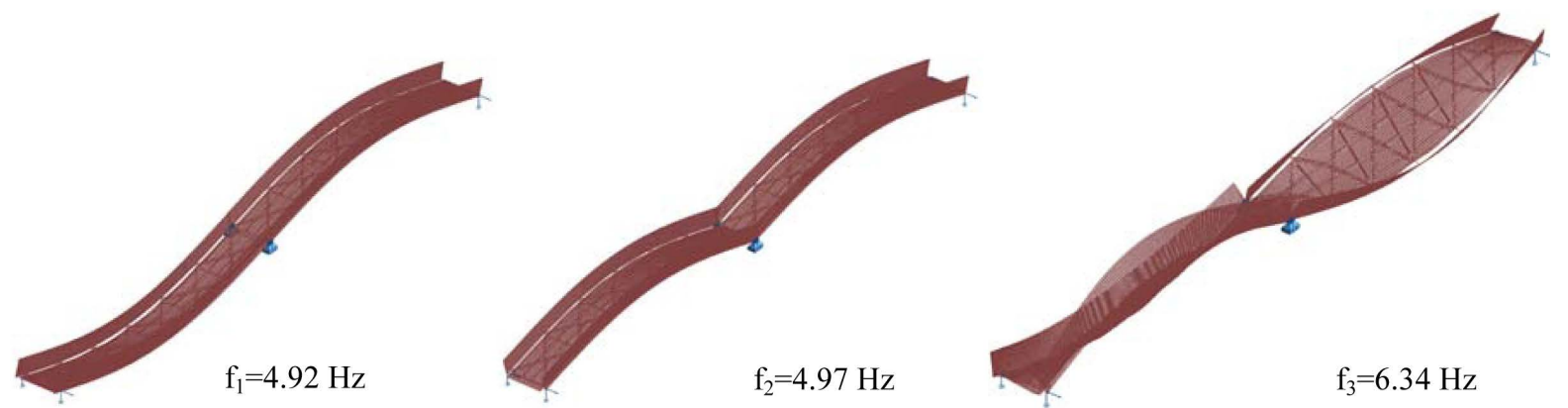

Figure 13. The pedestrian-inducted vibrations—analyzed footbridge with GFRP deck.
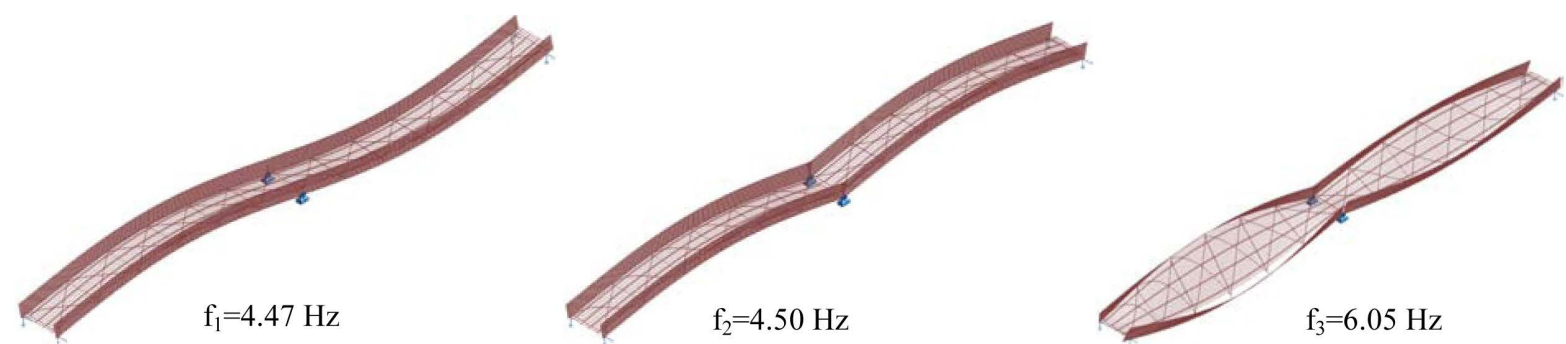

Figure 14. Footbridge with wooden deck—-footfall analysis. 
Table 2. The results of modal analysis.

\begin{tabular}{ccc}
\hline The $\mathbf{1}^{\text {st }}$ three modes & Wooden deck [Hz] & Composite deck [Hz] \\
\hline 1 & 4.42 & 4.88 \\
2 & 4.48 & 4.94 \\
3 & 5.34 & 5.16 \\
\hline
\end{tabular}

Table 3. Results of footfall analysis.

\begin{tabular}{ccc}
\hline Footfall & Wooden deck [Hz] & Composite deck [Hz] \\
\hline 1 & 4.47 & 4.92 \\
2 & 4.50 & 4.97 \\
3 & 6.05 & 6.34 \\
\hline
\end{tabular}

The rules introduced in European standards require verification of natural frequency and level of vibrations of the footbridges. According to EN 1990/A1 verification the vibration comfort criteria should be performed when the fundamental frequency of the footbridge is less than $5.0 \mathrm{~Hz}$ for vertical vibrations and $2.5 \mathrm{~Hz}$ for horizontal and torsion vibrations. In the cases of medium and large span steel footbridges the fundamental vertical vibration frequency is very often less than $5.0 \mathrm{~Hz}$. With these reasons the verification of the vibration comfort criteria becomes obligatory for almost all steel footbridges. Fundamental parameters determining the intensity of vibration perception by human are: vibrations amplitude, frequency characteristic of the vibrations, direction of the vibrations, vibrations impact time (exposure time), repeatability of the vibrations, human activity. It should be noted that the recommendations of the EN 1990/A1 exclude the impact of the frequency characteristic of the vibrations and type of human activity on the permissible amplitude of the vibration acceleration. In some cases, the vibrations with amplitudes equal to the values recommended in EN 1990/A1 can be clearly felt by walking and very clearly by standing pedestrians. It is necessary to define the appropriate and accurate criteria [7]. The analyzed footbridge with GFRP composite deck is suitable with EN 1990/A1 normative rules.

\section{GFRP Decks for Road Bridge}

The use of fiber composites has great potential in bridge building [4]. The possibility of pre-assembling in the hall allows for rapid installation on site, low costs of maintenance, durability are very promising. For example in 2011 Karrebaksmide Bridge in Denmark with GFRP deck and steel main structure of moving span was constructed. Germanic Hesen bridge with GFRP deck by Fiberline ASSET 600 system was erected in 2008 (Figure 15). Many steel footbridges with light GFRP deck were built in Denmark and Nederland, some of road bridges, in this system, were made in Great Britain, USA, Canada [4]. Traditional bridge decks are heavy and have poor durability but effective connection systems and better durability of pavement (by polymer concrete), which covered GFRP deck, at road bridge structures are very important directions in searching scale. GFRP deck is good alternative for old steel bridges, which need to exchange heavy old deck. Imposing strength values and fatigue parameters and all material properties (Table 4) [8] of glass fiber polymer give possibilities of modern shape of bridge structures using long-life material and coexistence traditional main part of bridge-steel girders with light, anticorrosion deck. Bridge engineering creates new directions in composite materials applications by strength parameters investigation. There are GFRP bridge deck panels for using in bridge structures with long durability. The capacity of GFRP is determinate by glass fiber's pultruted direction in polymer matrix.

\section{Conclusion}

GFRP composite decks are promising, interesting alternative for bridge structures, modern footbridges and bridge which needs modernization. Technical parameters of GFRP material create longer durability of bridge decks. The author's material research showed anisotropic structure of GFRP, which has determined strength and stiffness values of GFRP profiles. The analyzed footbridge with GFRP composite deck is suitable with EN 1990/A1 normative rules-vertical vibration frequency has been less than $5.0 \mathrm{~Hz}$. The modal analysis of vibrations is very important and interesting in bridge designing process. With the progress of ever-increasing span of foot- 


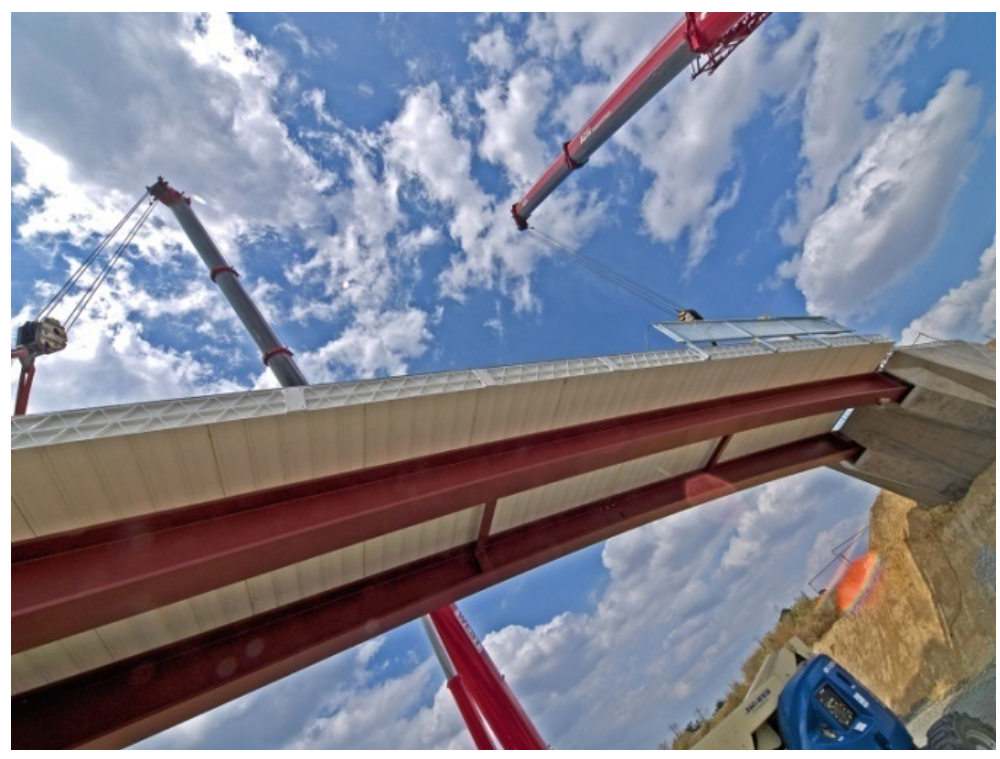

Figure 15. Germanic Hesen bridge-composite structure steel beams with GFRP deck.

Table 4. Material properties, strength \& stiffness values (GFRP Fiberline profiles).

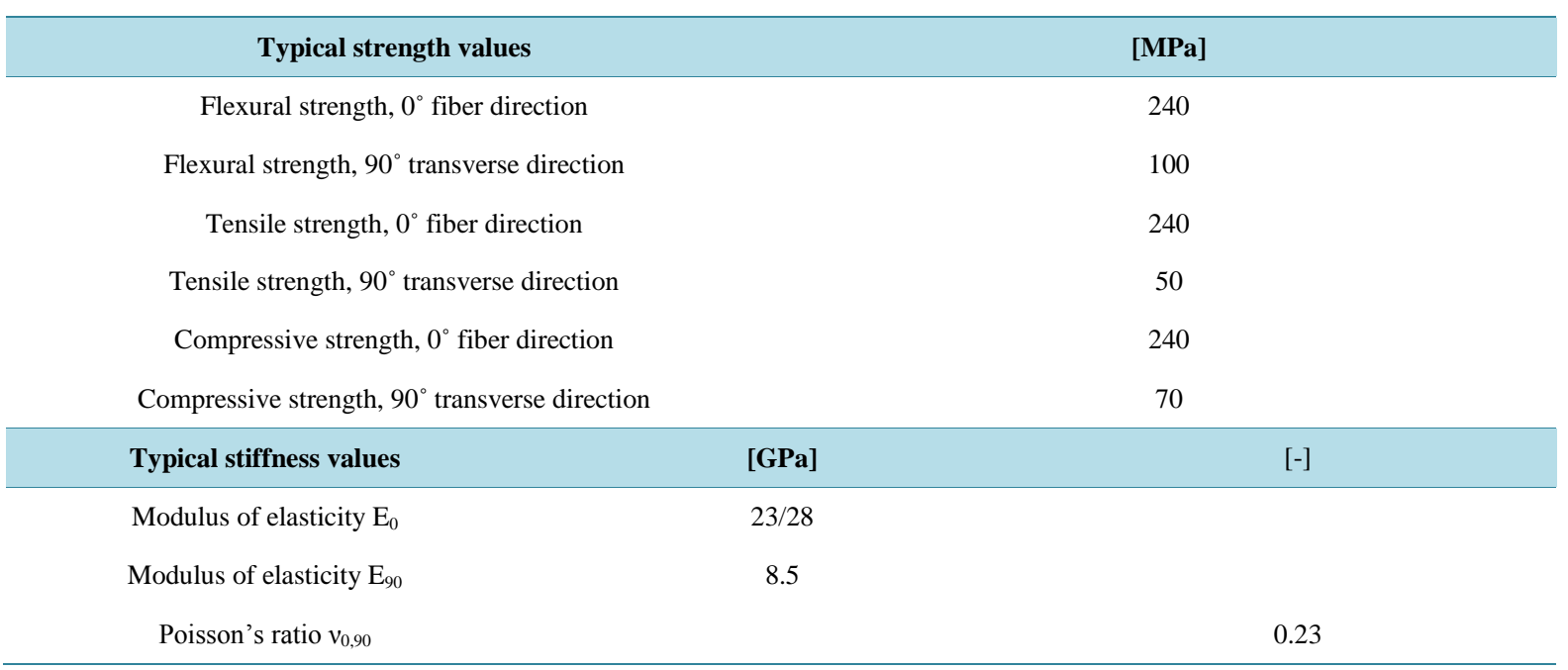

bridges and the application of modern light and high strength materials, as well as the pursuit of bridge esthetic in urban areas, the fundamental frequency of modern flexible footbridges decreases significantly. Present footbridge structures in the world are like explosion of modern engineering calculation and material parameters. Nonstandard solutions need special verification process. New conceptions of GFRP in footbridge projects must be explored by FEM model analysis.

\section{References}

[1] Keller, T. and Schollmayer, M. (2004) Plate Bending Behavior of a Pultruded GFRP Bridge Deck System. Composite Structures, 64, 285-295.

[2] Sebastian, W. and Keller, T. (2013) Influences of Polymer Concrete Surfacing and Localized Load Distribution on Behavior up to Failure of an Orthotropic FRP Bridge Deck. Composites Part B: Engineering, 45, 1234-1250. http://dx.doi.org/10.1016/j.compositesb.2012.07.050

[3] Vovesny, M. and Rotter, T. (2012) GFRP Bridge Deck Panel. 23rd Czech and Slovak International Conference Steel Structures and Bridges 2012, Podbanské, 26-28 September 2012. 
[4] Stankiewicz, B. (2014) Kompozyty GFRP w konstrukcjach mostowych. Monografia, Oficyna Wydawnicza Politechniki Opolskiej, Opole. (In Polish, in Proceeding)

[5] Stankiewicz, B. (2012) Composite GFRP Deck for Bridge Structures. 23rd Czech and Slovak International Conference Steel Structures and Bridges 2012, Podbanské, 26-28 September 2012.

[6] Stankiewicz, B. and Tatara, M. (2014) The Possibilities of Glass and GFRP in Footbridges. 5th International Conference Footbridge 2014, London, 16-18 July 2014.

[7] Pantak, M., Jarek, B. and Sredniawa, W. (2012) Application of EN 1990/A1 Vibration Serviceability Limit State Requirements for Steel Footbridges. 23rd Czech and Slovak International Conference Steel Structures and Bridges 2012, Podbanské, 26-28 September 2012.

[8] Stankiewicz, B. (2014) Composite Material GFRP and Ductal in Decks of Bridge Structures. Journal of Materials Science and Engineering A, 4, 282-289. 
Scientific Research Publishing (SCIRP) is one of the largest Open Access journal publishers. It is currently publishing more than 200 open access, online, peer-reviewed journals covering a wide range of academic disciplines. SCIRP serves the worldwide academic communities and contributes to the progress and application of science with its publication.

Other selected journals from SCIRP are listed as below. Submit your manuscript to us via either submit@scirp.org or Online Submission Portal.
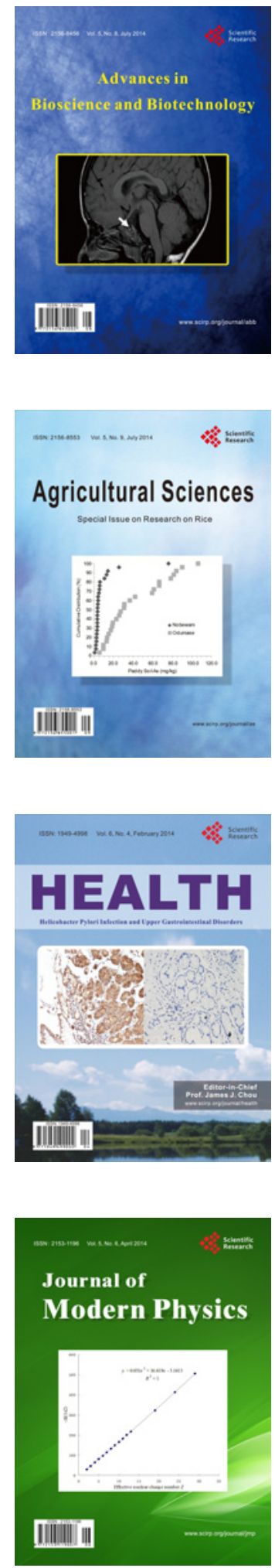
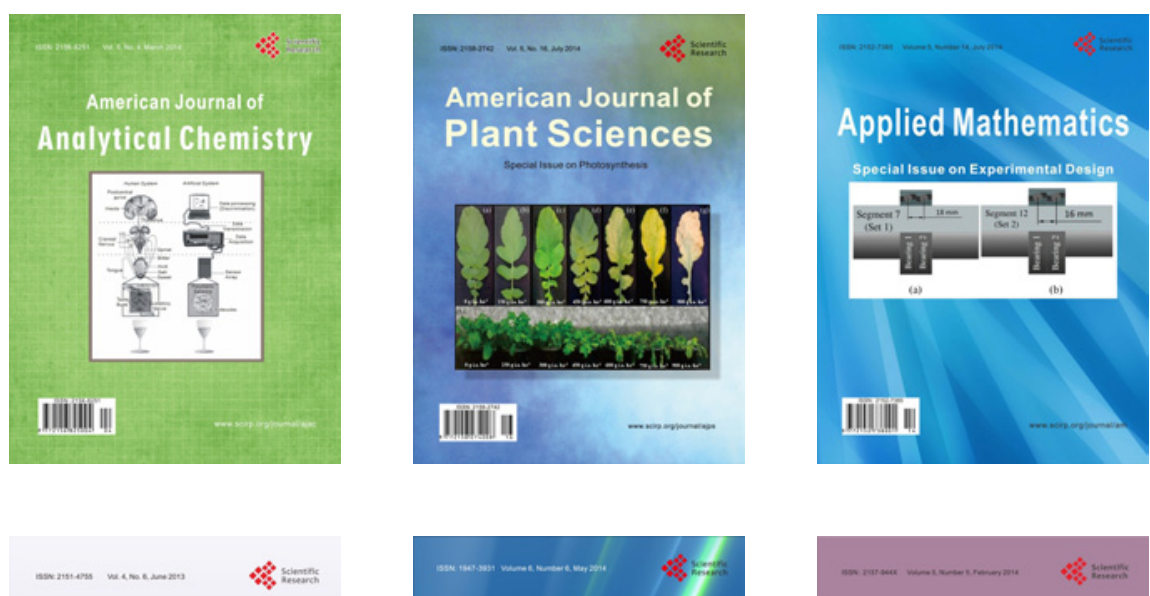

Creative Education
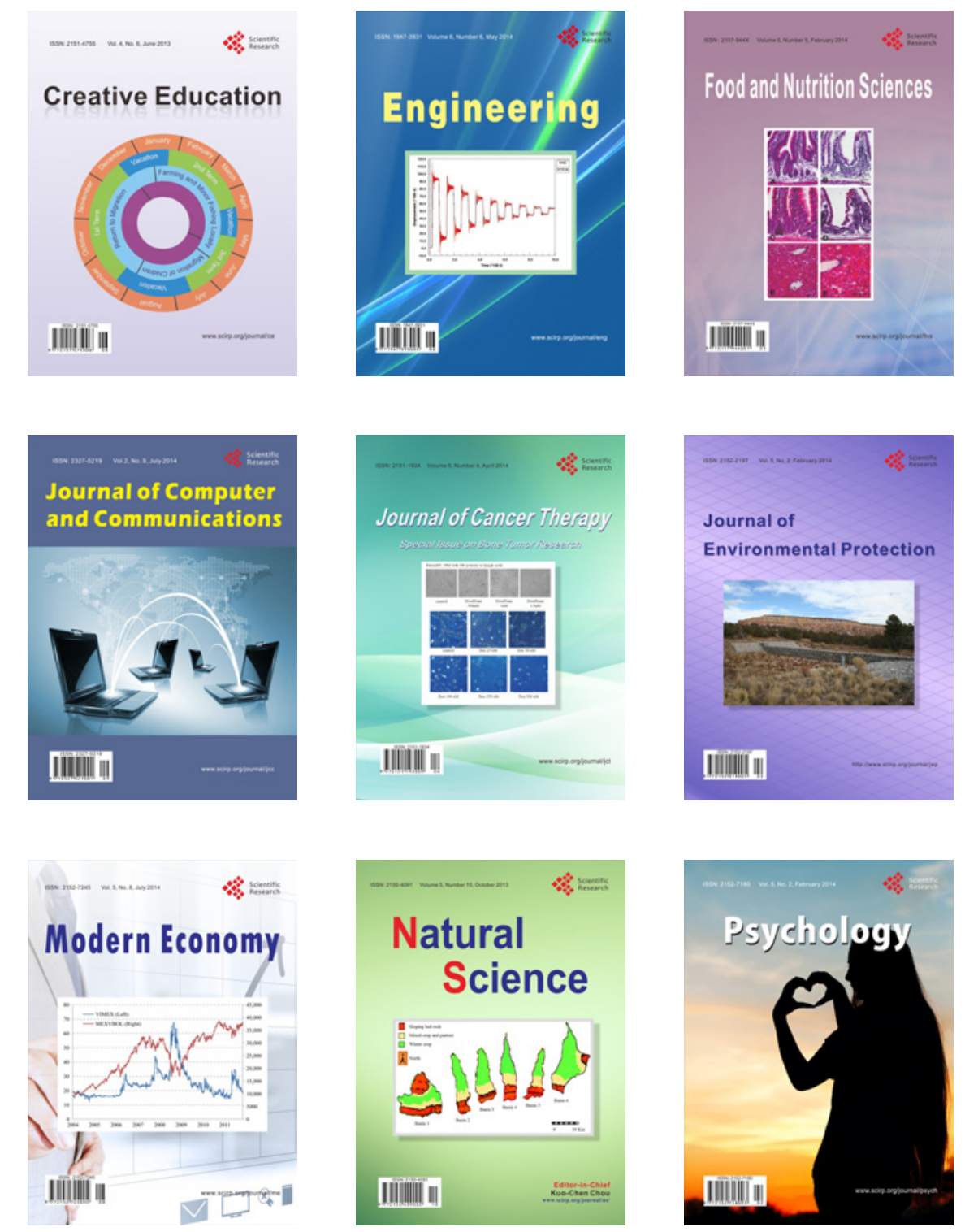